\title{
Who and what should manage each person's lifelong outcome information
}

Keywords: disability registry, PHR (personal health record), individual life course, wearable device, outcome information, vulnerable health

\section{Introduction}

"The coronavirus pandemic has shown us a new world; one where the status quo no longer exists," the UNDP (United Nations Development Programme) Administrator Achim Steiner said. ${ }^{1}$ The pandemic presents both an enormous challenge and tremendous opportunities for reaching the 2030 Agenda and the SDGs (sustainable development goals). ${ }^{2,3}$ Efforts toward the realization of SDGs and Society 5.0 (IT society) ${ }^{4}$ will be promoted in various fields more and more. In Japan, e-Japan, that is, an initiative for all citizens to actively utilize IT and maximize its benefits, started in 2001. In the medical field, the PHR (Personal Health Record) service model based on the consent of the individual is beginning to be applied to some diseases. ${ }^{5,6}$

On the other hand, in Japan, where the population is aging, the shift from "Cure" to "Care" is required" under the UHC (Universal Health Coverage), which is said to be a model for the world. ${ }^{8}$ In such a mature society Japan, the authors have been proposing that a "disability registry data base (hereinafter referred to as "disability DB")" would be needed as an information base to support each resident's self-management. ${ }^{9-12}$ In this study, "outcomes" among the information necessary for building, utilizing, and deploying the disability DB is focused. In this study, we examined the improvement measures about the outcome information that has pointed out that the information had been relatively lacking.

\section{Outcome information}

While the output is "output result," the outcome means "result/ effect," epidemiologically. The "outcome goals" in Japan's disability welfare plan ${ }^{13}$ may be positioned as outcome information in the implementation and evaluation of each policy. So what are the "outcomes" in the disability DB? The outcome goals of the policies presented by the government are the following five: (1) Transition of facility residents to community life, (2) Construction of a comprehensive community care system for mental disorders, (3) Development of community life support bases, etc. with an eye on the increasing severity and aging of persons with disabilities and "after the death of their parents," (4) Transition from welfare facilities to general employment, etc., (5) Establishing a system to support children with disabilities. Then, what are the outcomes that should be entered in the "personal life course" called the disability DB? Many of them seem to be related to "the happiness of life." If it is an input item that you have the opportunity to input frequently, it might be something like "ease of daily life," "comfort of the day," "rewarding of everyday life," etc.

As the authors have already mentioned, in recent years, the concept of disability has expanded and the concept of health itself has changed along with changes in social conditions such as the medical economy.
Volume 4 Issue 6 - 2020

Tachibana Tomoko

Center for Public Health Informatics, National Institute of Public Health, Japan

Correspondence: Tomoko Tachibana, MD, MPH, PhD, Center for Public Health Informatics, National Institute of Public Health, 2-3-6 Minami, Wako city, Saitama prefecture 35I-0197, Japan, Tel +8I-48-458-6206, Fax +8I-48-469-0326,

Email tachibaa.t.aa@niph.go.jp

Received: December 04, 2020 | Published: December 15, 2020

Disability is by no means a "health event to avoid," as it used to be. People face various challenges, physically, mentally and socially, in the course of their lives. ${ }^{11,14,15}$ Therefore, as a result, they may spend their lives afterwards with various "sequelae, disabilities, and chronic injuries/diseases." The fact that "what you can't do" increases will be also common to "aging." Even if someone is "a person with vulnerability" who has such disabilities, he/she can control his/her own life to make his/her life as comfortable as possible. From here on, "disability" would like to be used in this paper as "vulnerable health" as we had suggested. In other words, please note that from here, "disability" in this paper is regarded as "people who live with physical, mental, and social challenges related to health."

Values vary from person to person. Therefore, of course, the outcomes of each aim will vary from person to person. ICT (Information and Communication Technology) may be useful for inputting information in such cases (Figure 1). ${ }^{16}$ In other words, if you use the cloud and mobile devices that have become widespread in recent years, you can expect to continuously collect detailed personal outcome information. In addition, by developing and utilizing the iPhone application, it is possible to collect more efficient and highquality outcome information. For example, on the smartphone drawn on the right of (Figure 1), develop a dedicated "disability app" with questionnaire items. In case, if you download it in advance, how about allowing individuals who are recipients of disability welfare services to enter the required outcome information? Outcomes would be indicators of life's well-being and comfort. If so, how accurately can a third party grasp the outcomes for each individual? In order to enhance the outcome information, it will be important for "the person $\mathrm{him} /$ herself" to enter it. However, for people living with disabilities, sometimes it may not be possible for them to enter information on their own. At that time, if the individual is willing to answer but cannot enter each response, the problem might be solved if he/she agrees to cooperate with the social capital, ${ }^{17}$ that is, human relationships such as trust and relationships, local community organizations and volunteer organizations, etc., around him/her. 


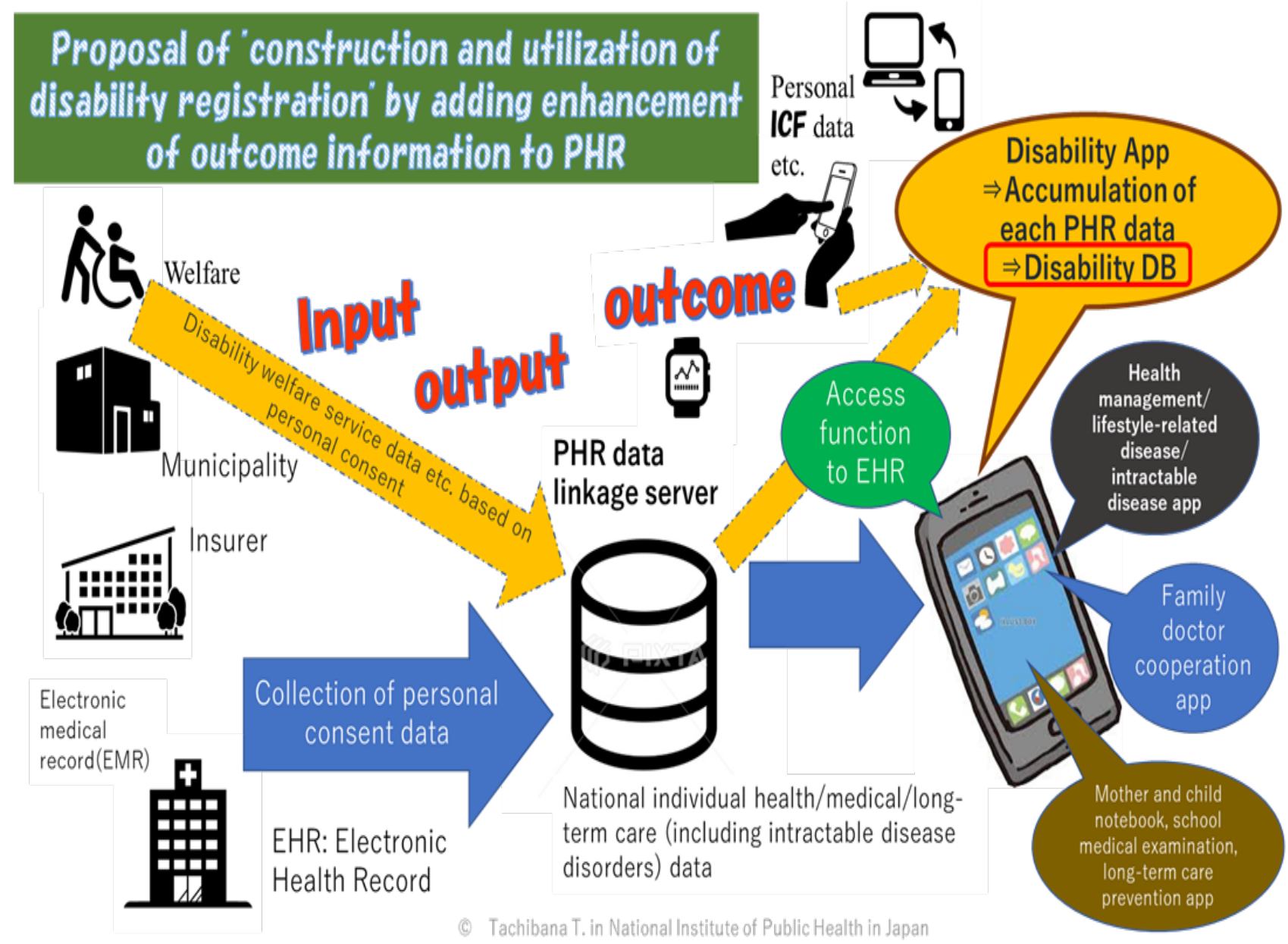

Figure I Proposal of PHR service model based on the consent of the person (Quoted from reference I3).

\section{Conclusion}

From an informational point of view, the ideal way of disability DB by PHR is explored. The data in it can be expected to contribute not only to the evaluation of interventional effects, but also to the reduction of the response burden by wearable devices and the collection of answers based on the ICF (International Classification of Functioning, Disability and Health) [18]. In a mature society Japan, "disability" should be understood as "people who live with physical, mental, and social challenges," which has needs to be disseminated. To achieve the SDGs, the construction and utilization of disability DBs by PHR seemed to be a priority issue that should be realized as soon as possible in Japan.

\section{Acknowledgments}

None.

\section{Conflicts of interest}

This study was supported by the Taiju Life Welfare Foundation's 52nd Medical Grant, "Study on the Development and Evaluation of a Self-Management Program to Support the Social Life of Patients with Epilepsy after Stroke." For this study, none of the authors have a COI status to disclose.

\section{References}

1. The United Nations Development Programme (UNDP). Coronavirus vs. inequality. How we'll pay vastly different costs for the COVID-19 pandemic. 2020.

2. The United Nations Development Programme (UNDP). COVID-19 and the SDGs. 2020.

3. United Nations. Sustainable Development. The 17 goals. 2020

4. Cabinet Office. Society 5.0. Japanese. 2020.

5. Roehrs A, Costa CA, Righi RR, et al. Personal Health Records: A Systematic Literature Review. J Med Internet Res. 2017;19(1):e13.

6. Abe S. Japan's strategy for global health diplomacy: why it matters. Lancet. 2013;14;382(9896):915-916.

7. Miyata H, Satoshi Ezoe, Manami Hori, et al. Japan's vision for health care in 2035. Lancet. 2015;27;385(9987):2549-2550.

8. The World Bank. Universal Health Coverage for Inclusive and Sustainable Development. 2020.

9. Tachibana T, Tachibana H. The Long-Term Spontaneous Course of Severe Traumatic Brain Injury Incurred at age 16 by a 47 -Year-Old Physician: Investigation into Planning a Long-Term Prognosis Study of Childhood Traumatic Brain Injury. International Medical Journal. 2012;19(4):321328. 
10. Tachibana T, Suehiro E, Suzuki M. Policy review on "Disability Registry" construction as a Prognosis/Outcome indicator in medical database: Toward the Proposed "Definition of Health for a Care-focused Mature Society. Neurotraumatology. 2018;41:1-15.

11. Tachibana T. A Study on Evaluation of Post-stroke Self-management Support Program for Social Life Support. Towards building Supporting Systems for Self-Help/Mutual-Help in Communities. Health Educ Public Health. 2020;3(4):313-317.

12. Tachibana T. A Suggestion to Promote Public Health Activities in the Mature Society of Japan. For Establishment of a Self-Management Support System. Health Educ Public Health. 2020;3(2):282-287.

13. Tachibana T. How to Build, Utilize and Deploy the "disability registry" to Enhance the PHR System throughout Life in Japan-Who manages each person's lifelong outcomes?. Health Educ Public Health. 2008.
14. Ministry of Health, Labour and Welfare. Achievement goals and activity indicators. 2020.

15. World Health Organization. WHO remains firmly committed to the principles set out in the preamble to the constitution. 2020.

16. World Health Organization. Disability. 2020.

17. Tachibana T. How to Build, Utilize and Deploy the "disability registry" to Enhance the PHR System throughout Life in Japan-Who manages each person's lifelong outcomes? Health Educ Public Health. 2008.

18. Baum FE, Ziersch AM. Social capital. J Epidemiol Community Health 2003;57:320-323.

19. World Health Organization. International Classification of Functioning, Disability and Health (ICF). 2020. 